\title{
Developmental psychopathology: a framework for planning child mental health
}

\author{
DONALD J. COHEN and ERNESTO CAFFO
}

The scientific study of children's development provides a framework for national planning of mental health services. Research on developmental psychopathology emphasizes the intimate connections between biological and psychological development, the role of parents and other caregivers in shaping children's competence, the social and historical context of development, and the psychobiological pathways that lead from one stage to another and that are marked by continuities and discontinuities (Cicchetti \& Cohen, 1995; Cicchetti \& Rogosch, 1996). This developmental knowledge illuminates the sensitive points when risk is likely to be expressed, as well as optimal times for prevention and intervention.

At each epoch in a child's life, from gestation through adolescence, children and families are confronted by expectable challenges as well as threatening risks and vulnerabilities. When problems arise, the child and family mobilize their own modes of adaptation (Masten et al., 1990). As tasks of personal and family development are mastered, the child and parents can move ahead with new competence and confidence. Failures in adaptation, however, set the stage for the child and parents to move further from the normal growth curve and to follow a trajectory that leads to increasing dysfunction. Failure in a developmental task is a risk factor for the next phase of development. For example, children who fall to learn how to read by ace 8 are likely to then fall in school and drop out by age 12 or 13 . Stage by stage, strengths generally build upon strengths, and risks are compounded by failures.

Fragile infants in impoverished homes slip behind developmentally, with each delay setting the stage

Address for correspondence: Professor Dr. D.J. Cohen, Yale Child Study Center, 230 South Frontage Road, PO Box 207900, New Haven, Connecticut 06525 (USA).

$\mathrm{Fax}+1203$ 785-7402.

E-mail: Donald.Cohen@Yale.edu for subsequent problems. Small, vulnerable, drug-exposed infants who are raised in chaotic and dysfunctional families fail to thrive as infants. They will be 2 or 3 years behind in language and social skills when they reach school, and they are likely to fail academically and to drop out of school early in adolescence, to become the young parents of the next generation of infants at risk (Mayes \& Granger, 1996; Mayes \& Bornstein, 1998). Today, millions of children like this are on a trajectory from birth that will lead them from one failure to another. It is no surprise when they succumb to drugs, prostitution, and crime in adolescence.

This perspective emphasizes the multigenerational nature of the child mental health field. Risk and protective factors are transmitted from one generation to the next. Yet, not all children at risk become impaired, and policy planners and clinicians must be aware of the dangers of any linear, mechanistic model that could become a self-fulfilling prophecy of doom for individuals or groups of stigmatized children (Cicchetti, 1994). Mathematical methods for assessing the likelihood that a child will succeed or fail are applicable only to large populations. Using empirical information about correlations between factors and outcomes, it is possible to calculate the likelihood (odds ratio) that one specific risk factor (such as exposure to maltreatment) will either increase or decrease the chance that a child will have an adverse outcome. Yet, in the real world, there are very many interactions among factors, modifying variables, and other complications in prediction. Thus, great care must be used in making any generalization about the effects of any single factor or experience for specific children.

From clinical and research studies, we know that some children are able to overcome external challenges and to learn and achieve, even in the most difficult situations. This type of decreased vulnerability may relate to the age of exposure (e.g., babies are 
more sensitive to separations or to poor nutrition), biological differences (e.g., some children are genetically at higher risk for disorders), and dosage effects (e.g., even in situations of trauma, the children who are closest to the event are at highest risk). Sometimes, there are hints about the source of resilience for particular children, e.g., a determined parent, a caring mentor, unusual talents or intelligence. By studying children who move ahead, in spite of adversity, clinical investigators can learn about inborn strengths and protective factors. This knowledge can lead to better preventive programs.

Detailed knowledge of physiology and mechanisms of transmission of disease guide public health interventions in pediatrics. Similarly, knowledge of normal tasks of development, as well as the threats to specific individuals and groups must guide psychiatric public health. The pathophysiological, public health approach to children's mental health provides a scientific and relatively non-ideological, pragmatic framework for community- and family based interventions.

Available information already supports the concept that support at each phase of development and early detection of difficulties are far more efficient and clinically sensitive - for the child, family, and society - than later attempts at remediation or treatment. However, no child or group should ever be ignored. Communities and clinicians can offer effective care for children who are already seriously disturbed, such as street children, abused children, and children who are truant from school and are already delinquent or in reformatories.

\section{THE FIRST YEARS OF LIFE}

Children provided with warm care and attention become attached to their parents and then to one or two adults who take care of them on a regular basis. The more securely children are attached, the more easily they can cope with new experiences, including the normal, small upsets, such as separations from parents. However, no degree of warm attachment will immunize a child from the greatest tragedies that occur during war or serious illness (Apfel $\&$ Simon, 1996). The experiences during the first years of life are especially important because they lay down the foundations for all future development (Cicchetti, 1994). Fortunate children who have been loved, stimulated, talked with, comforted, and even predictable care will see the world as basically safe and secure, will feel valued and effective, will have trust in themselves and others, and will be able to use their intellectual potentials to their limits.

Children who have had difficult experiences are of greatest concern to policy planners because of their increased likelihood of serious problems in their social, emotional, or intellectual development. In subsequent years, there may be opportunities for their earlier brain and behavior problems to be reshaped. Children with low self-esteem from repeated failures and neglect can blossom if they are provided with mentors and chances for success, and anxious children can be helped with therapy and emotional supports. Overactive children can learn how to calm down in kindergarten. Clinicians and educators should always nurture every child's potential for recovery. But they cannot count on the success of such renovations when maladaptive processes have gone on too long or too badly.

While the first years of life are extremely important in shaping children's development, there is no magic period of development. Children who have had a good start in life require continuing support from families and community. And children who have started life with difficulties may develop compensatory self-righting processes. At each phase, children require developmentally suitable care from parents and others, continuity of relations, affection, intellectual stimulation, protection from harm, and security. With maturation, the child's world widens to include peers, neighborhood, and the broader society. These progressively take over some of the influence and even the authority earlier vested in parents. Thus, developmental support begins to include the media, police who provide security, and employers who offer jobs and a future role in the economy.

\section{SOCIAL CHANGES AND TRAUMA}

During the past decades, the «normal, expectable environments» for children have changed dramatically. Throughout the developed world, it has become less likely that children will have opportunities for continuity of nurturance by two loving parents throughout the developmental years. These social changes are affecting families of all social classes. One century ago, in the United States and in Europe, the average family had many children (seven in the United States), two parents, and a mother at home to care for the children. Divorce was rare. Today, 
in Europe and the United States, the average family has two or fewer children, both parents work, and infants are placed in daycare the first year or two of life. Many children are born out of wedlock and divorce rates in the United States are reaching $50 \%$. Today, it has become common for children to live with only one parent sometime during their childhood.

The way in which parents generally provide care for their children and the needs of children have evolved, in parallel, over hundreds of thousands of years of human evolution. During the past century, society has changed much more rapidly than our brains and behavior can evolve. As families have become smaller and more mobile, many young families can no longer turn to their own parents for help and guidance. Increasingly, there must be social systems to support young families and to intervene when there are problems. During the past decade, new models of intervention have been devised. These emphasize prevention, family support, and the integration of a spectrum of community-based services for those with serious problems. These models also underscore the synergism of professionals, parents, and the community and draw upon the expertise of many different professions, including child psychiatry, pediatrics, social work, nursing, psychology, childcare, and others.

In addition to these pervasive changes in family life, the lives of children during the past decade have been burdened by many risks, including newly emergent risks. These include the impact of urban violence, multigenerational poverty, poor living conditions, bad nutrition, drugs and AIDS, abuse and neglect, child labor and exploitation, and the impact of parental physical and psychiatric illness on children. Also, children have become the major victims of political upheaval in Africa, Asia, Europe, and South America. Indeed, during warfare, women and children are no longer spared but have increasingly been specifically targeted as victims. Thus, children are killed in schools and bombed in hospitals, and they are disproportionately represented among those who are hit by shells or exploded by landmines. Today, millions of children are refugees and live in camps or as undocumented aliens, often separated from their parents by intentional government policy. Traumatized by war in their own homelands, they are then exposed to illness, danger, lack of schooling, and the risks of sexual and other types of exploitation. There is a cascade of developmental disruption from acute and persistent trauma (Pynoos et al., 1995).

When a child is abused at home and victimized in the community, he is unable to evoke any secure, emotional, internal portrait of a caring adult. His internal world becomes suffused with frightening images and fantasies. Children who grow up attacked from the outside may turn their passivity into active forms of aggression to preserve their sense of selfhood and respect. Thus, children move from being witnesses and victims of violence to becoming perpetrators of violence. Their aggression allows them to maintain a sense of personal coherence and effectiveness. Often, such children are recruited into youth gangs and paramilitary groups, and they organize their entire lives around the themes of retaliation and revenge.

\section{TREATMENT, SERVICES AND PUBLIC POLICY}

Child mental health services and systems are relatively young. The pioneers in child psychiatry, child psychoanalysis, pediatrics, and social work began to explore the vast domain of childhood emotional, developmental, and psychiatric disorders only during the 1920's and 30's. Formal training programs in child psychiatry were established only during the 1950 s, and systematic research in the field of child mental health is only several decades old. Today, in many nations, child and adolescent psychiatry is still emerging as a distinct profession; in the developing world, there are few child psychiatrists, psychologists, social workers, child psychiatric nurses, or special educators.

In spite of the complexity of childhood disorders and the paucity of professionals and resources, there have been major advances in treatment for broad classes of disturbances and conditions. Recently, child psychiatrists have been able to use effective medications for psychiatric disorders, in addition to psychosocial interventions. These treatments can ameliorate specific symptoms, reduce the burden of suffering, and markedly improve the quality of life of children and families. A challenge for clinical researchers is to carefully evaluate the available treatments and approaches to determine which are most effective for specific children and to define areas in need of more systematic research.

However, we have also recognized the limitations of some traditional approaches to clinical care. For 
example, intensive, long-term, individual psychotherapy cannot be delivered to the vast number of children in need. Also, these traditional approaches may be of only limited effectiveness for children at highest risk, who are constantly exposed to trauma and adversity. During the last several years, mental health workers have been developing alternative methods of delivering care; there is a consensus on the importance of reducing barriers to services and providing, quick, effective intervention at times of crisis. Treatment innovations include the use of schools as the base for family and child services, new methods of early intervention for vulnerable children, new curricula for children with special needs, and partnerships between mental health workers and other groups concerned about children in trouble, including the police (Marans, 1996).

Further research and experimentation are needed to advance the care of children at highest risk. Developmental, behavioral, and mental disorders are costly both financially and in terms of human suffering. Hundreds of thousands of dollars, and even millions of dollars, may be spent on the lifelong care of a child with a serious developmental or psychiatric disorder. Yet, very few nations devote substantial funding for research on developmental psychopathology or basic studies of brain and behavioral development; even less is provided for translating research findings into systems of intervention and treatment. Yet, improvement in the prognosis for the most serious conditions - such as autism, language and learning disorders, and intellectual handicap completely depends on advances in basic and applied research. The lack of generally effective treatment is clear even in relation to the more frequent, later-onset difficulties. For example, the majority of teenagers with drug and conduct disorders do not respond to currently available therapies, nor do we know how to treat parents who are persistently abusive or to repair the psychobiological damage to children who have experienced years of abuse.

Second, systematic research is needed on prevention and new approaches to treatment and intervention. There already are effective methods for reducing risk. These include good prenatal and childhood health and nutrition, suitable schooling and continuity of family care. We do not know how to prevent the major disorders such as autism or suicide or the conditions that afflict children in high-risk situations who are often burdened by both constitutional and environmental risks

To make use of emerging knowledge, the profes- sions dealing with children require training that is soundly based on basic and clinical knowledge, and they need opportunities for continuing education. New knowledge about children's brains and development, about developmental psychopathology and about treatments will not be useful to children unless the professions who serve them are well informed about translating knowledge into practice. This includes teachers and social workers, as well as police officers, childcare workers, nurses, pediatricians, and mental health clinicians. As a voice for all children, child mental health professionals can do a great deal to decrease risk factors and promote protective factors for populations and individuals. Information about risks, causes, and treatments is vital for government at all levels and of all political persuasions. Governments need authentic information about the state of children, the institutions that serve them, and the preventive and interventive programs that work. The critical evaluation of such data is an important part of shaping rational social policy.

There is a great deal that governments already can use to reduce the burden of suffering and to create opportunities for healthier development. Governments should promote early and sustained healthcare, emotional and intellectual stimulation, regularity and structure, and the availability and support of families. It is critically important to protect children from danger and to provide shelter and continuity of care, including family reunification for refugees and a sense of hope within the mainstream of society for all children. Strengthening democratic society requires children who have been treated fairly, who internalize the values of cooperation and sharing, and who have the capacities and education to become productive and well-compensated workers. Children and adolescents need to feel that there is a basic social structure that is fair and that offers a chance of success, if they apply themselves and use their abilities well.

Today, in all developing nations, the rich are getting richer and the gap between rich and poor is increasing. In many nations, the elderly are rich and financially secure and young families are increasingly burdened and poor. In this situation of increased concentration of wealth in a very affluent upper class, an increasing, sense of alienation and bitterness is transmitted to children. By adolescence, the young and poor who feel left out of the mainstream become cynical, socially disconnected, and a threat to the security of others with whom they feel no mo- 
ral or social engagement. These social facts are of vital importance to those who lead our governments.

This public health perspective on the social development of children is increasingly important in relation to the future security of nations. Throughout the world, leaders are recognizing that a nation's most critical natural resource is its children. To succeed the future, nations will need physically and emotionally healthy children who are intellectually prepared for modern technology. At the beginning of this century, child advocates and government leaders predicted that this would be the century of the child. Who would have predicted the holocaust, with one million children murdered, or the staggering burdens of racism throughout the world? Now, looking backwards at the fate of children during this century, with millions of children caught in wars, living on the street, and abused in their own homes, we can see that this has been a grim century indeed for children and nations.

Child psychiatrists, psychologists, educators, and social workers have specialized, developmental knowledge to share and important care to provide. They are the natural spokespeople for children at risk and those who have been traumatized. Scientific knowledge about developmental psychopathology can be a potent resource for child advocacy on behalf of children at risk as well as the mental health of all children in the community.

Acknowledgments. We appreciate many discussions with our colleagues in Modena, Telefono Azzurro and the Yale Child Study Center. This Editorial is adapted from our chapter: D. Cohen and E. Caffo, Developmental Psychopathology and Child Mental Health Services, in Young and Ferrari (ed.), 1998.

\section{REFERENCES}

Apfel R. \& Simon B. (ed.) (1996). Minefields in their Hearts: the Mental Health of Children in War and Communal Violence. Yale University Press: New Haven, CT.

Cicchetti D. (ed.) (1994). Advances and challenges in the study of the sequelae of child maltreatment [Special Issue]. Development and Psychopathology 6(1).

Cicchetti D. \& Cohen D.J. (ed.) (1995). Developmental Psychopathology. Volume 1: Theory and Methods. Volume 2. Risk, Disorder and Adaptation. Wiley: New York.

Cicchetti D. \& Rogosch F. (ed.) (1996). Developmental pathways: diversity in process and outcome [Special Issue]. Development and Psychopathology 8(4).

Cohen D. \& Caffo E. (1998). Developmental psychopathology and child mental health services: risk and protective factors in children, families and society. In Designing Mental Health Services for Children and Adolescents: a Shrewd Investment (ed. J. Young and P. Ferrari), pp. 3-13. Bruner-Mazel: Philadelphia.

Marans S. (1996). The Police-Mental Health Partnership. Yale University Press: New Haven, CT.

Masten A., Best K. \& Garmezy N. (1990). Resilience and development: contributions from the study of children who overcome adversity. Development and Psychopathology 2, 425-444.

Mayes L. \& Granger R. (1996). Teratologic and developmental effects of prenatal drug exposure: alcohol, heroin, marijuana, and cocaine. In Child and Adolescent Psychiatry: a Comprehensive Textbook (ed. M. Lewis), pp. 374-382. Williams and Wilkins: Philadelphia.

Mayes L. \& Bornstein M. (1998). The context of development for young children from cocaine-abusing families. In Health Psychology of Special Populations (ed. P. Kato and T. Mann). Plenum Press: New York (in press).

Pynoos R., Steinberg A. \& Wraith R. (1995). A developmental model of childhood traumatic stress. In Developmental Psychopathology, Volume 2: Risk, Disorder and Adaptation (ed. D. Cicchetti and D. J. Cohen), pp. 72-95. Wiley: New York. 